\title{
ЦЕНТРАЛИЗАЦИЯ СИСТЕМЫ УПРАВЛЕНИЯ НА ПРЕДПРИЯТИЯХ ПО БУРЕНИЮ РАЗВЕДОЧНЫХ И НЕФТЕГАЗОВЫХ СКВАЖИН
}

\begin{abstract}
Аннотация: Статья определяет особенности предприятий нефтегазовой отрасли, созданных путем объединения производственных мощностей на постсоветском пространстве, потенциальные преимущества централизации управления на предприятиях, а также критерии оценки загрузки персонала. Приводится пример методики оптимизации аналогичных отделов на дочерних предприятиях крупной нефтегазовой компании с учетом потенциильного эффекта от ежегодной экономии затрат на оплату труда. Даются рекомендации относительно применения данной методики. Речь идет о совокупности мероприятий, которые базируются на увязке нескольких базисных элементов в разных формах. В данной статье автором был рассмотрен метод объективной оценки загрузки персонала на примере отдела бухгалтерского учета и отчетности, а также всего предприятия. Автор формулирует ряд выводов:1. Сегодня на предприятиях нефтегазовой отрасли, работающих на постсоветском пространстве и созданных путем объединения производственных мощностей, не всегда уделяется должное внимание эффективности и экономичности системы управления.2. С учетом долгосрочных перспектив развития нефтегазовой отрасли отсутствие экономичных и эффективных структур управления уменьшает привлекательность для инвестирования, увеличивает издержки предприятий, усложняет процесс модернизачии производства, уменьшает гибкость системы предприятий.3. Предлагается метод объективной оценки загрузки персонала, который является универсальным и позволяет учесть все факторы, оказывающие влияние на повседневную работу персонала. 4. Даются рекомендации относительно основных направлений цеентрализации функций управления предприятием.
\end{abstract}

Ключевые слова: экономика, стратегическое управление, централизация управления, оптимизация персонала, фонд оплаты труда, нефтегазовая отрасль, бизнес-процессы, реструктуризаиия, оптимизация, персонал.

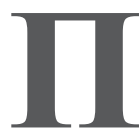
осле распада СССР бывшие страны-участницы, обладающие нефтегазовыми ресурсами, создавали национальные нефтегазовые компании на базе уже имеющихся производственных предприятий, многие из которых были организованы еще в послевоенное время и имели типичную организационную структуру и организацию бизнес-процессов для предприятий того времени. Но, не смотря на это, влияние таких факторов как: консолидация активов в девяностых годах, рост цен на энергоносители в двухтысячных годах, государственная поддержка компаний, а также устойчивое положение и высокая рентабельность отрасли позволило избежать масштабной оптимизации и реструктуризации предприятий. Таким образом, сегодня на предприятиях нефтегазовой отрасли, работающих на постсоветском пространстве и созданных путем объединения производственных мощностей, сохранилось большинство проблем, с которыми они достались в наследство от СССР. Тем не менее, учитывая общемировые тенден- ции к глобализации, укрупнению и объединению производственных мощностей, вопросы централизации управления и минимизации дублирования управленческих функций, снижении себестоимости и потребности в управленческом аппарате, а также поиск новых методов организации бизнес-процессов на предприятии приобретают все большую актуальность в мире 1. Кроме того, пренебрежение формирования эффективных и экономичных структур управления усложняет процесс модернизации производства и делает данные предприятия уязвимыми перед зарубежными предприятиями-аналогами. На сегодняшний день существует множество примеров, когда целые направления, например бурение разведочных и эксплуатационных нефтегазовых скважин, отдают зарубежным компаниям, таким как

\footnotetext{
Миронов Л.А. Состояние и развитие нефтегазового комплекса стран СНГ // НГСПинформ 2011, №11 / М.: Издательскопроизводственный комплекс «МИнИн Центр», 2011, стр. 1-5
} 


\section{Национальная безопасность - № 3(32) • 2014}

Shell, Exxon-Mobil и British Petroleum не только из-за технологической экспертизы и специфики работы, но также из-за лучшей организации бизнес-процессов, гибкости и быстроты выполнения задач, а также ряда других преимуществ.

Изучив и проанализировав литературу по вопросу реструктуризации и повышения эффективности системы управления на предприятия ${ }^{2}$, автор предлагает из всего многообразия методов, средств и факторов выделить наиболее важные и основополагающие (см. Таблицу 1).

Спектр средств, используемых в рамках реструктуризационных программ, весьма широк. В него входят и простые мероприятия, и долгосрочные, сложные программы целенаправленного развития фирменной культуры. В качестве базисных организационных элементов в рамках программ перехода к ресурсосберегающему производству, понимаются такие инструменты, которые далее не могут быть расчленены на мероприятия более низкого порядка. В ходе реструктуризации используется также ряд сложных, интегрированных организационных концепций. Речь идет о совокупности мероприятий, которые базируются на увязке нескольких базисных элементов в разных формах.

Оптимизация хозяйственных процессов любого вида включает следующие три основных действия: ${ }^{3}$

- Установление и распределение комплекса задач. Производится критическая оценка всех шагов, безусловно необходимых для выполнения задачи, интеграция нужных элементов в общий процесс, эффективный по времени, издержкам, обслуживанию клиента.

- Исключение или эффективная координация критически важных точек пересечения интересов. По возможности исключаются точки, замедляющие движение.

- Использование адекватной информационной технологии. В рамках оптимизации процесса на эту технологию возлагаются две задачи: во-первых, полная автоматизация рутинных процессов, во-вторых, обеспечение участников широкой

\footnotetext{
2 Мазур И.И., Шапиро В.Д. Реструктуризация предприятий и компаний // Справочное пособие // М.: Высшая школа, 2000, стр. 24-25; Bowman C., Asch D. Strategic management. L., 1987. P. 514;

3 Мазур И.И., Шапиро В.Д. Реструктуризация предприятий и компаний // Справочное пособие // М.: Высшая школа, 2000, стр. 28.
}

содержательной информационной базой и интенсивными коммуникациями.

Для наглядности автор приводит пример из практики, основанного на проекте снижения затрат крупной нефтегазовой компании Республики Азербайджан, участником которого он являлся ${ }^{4}$.

В нефтегазовой отрасли существует несколько основных этапов работ непосредственно перед добычей подземных запасов нефти и газа, в которых бурение разведочных и нефтегазовых скважин играет ключевую роль, позволяя обнаружить и добыть сырье на возможных участках, обнаруженных при проведении геологоразведочных работ и пустить в дальнейшую обработку. Буровые предприятия делятся на разведочные и эксплуатационные, которые в свою очередь подразделяются на морское бурение и бурение на суше. Но, не смотря на разную специфику у данных предприятий много общих черт, так например используемое оборудование, расходные материалы, технология, профессии и прочее. Кроме того, в случае с разведочным бурением: при успешном попадании в подземные залежи разведочные скважины автоматически переходят в состав эксплуатационных скважин, будь-то это море или суша. Таким образом, учитывая общие черты и схожесть данных предприятий, при определенных условиях возможно централизовать управленческие, финансовые, в определенной степени производственные, а также вспомогательные функции на предприятиях.

Компания ПНГДК имеет 7 дочерних предприятий, не обладающих статусом юридического лица, и разделенных по принципу концентрации на определенном направлении работ. Все предприятия находятся на незначительном расстоянии друг от друга, взаимосвязаны и сфокусированы на оказание услуг одному крупному клиенту (см. Таблицу 2).

Автор не случайно упомянул про фокусировку на оказание услуг одному крупному клиенту, так как, несмотря на количество предприятий, численность персонала и различие выполняемых функций, предприятия, приведенные выше в таблице, организованы и структурированы таким образом, чтобы обеспечить выполнение одного этапа из технологической цепи производства нефтегазодобывающей отрасли, которым является бурение скважин. Этап бурения подразделяется на ряд подэтапов, включающих:

\footnotetext{
4 В целях неразглашения конфиденциальной информации названия предприятий были заменены на вымышленные.
} 
Систематизация современных организационных мероприятий

Таблица 1.

\begin{tabular}{|c|c|c|c|}
\hline \multirow[b]{3}{*}{$\begin{array}{l}\text { Базисные } \\
\text { организа- } \\
\text { ционные } \\
\text { элементы }\end{array}$} & \multicolumn{3}{|c|}{ Организационный инструментарий } \\
\hline & $\begin{array}{c}\text { Структурные } \\
\text { факторы }\end{array}$ & $\begin{array}{c}\text { Человеческие } \\
\text { факторы }\end{array}$ & $\begin{array}{c}\text { Учет требований } \\
\text { технологического } \\
\text { менеджмента }\end{array}$ \\
\hline & $\begin{array}{ll}\text { - } & \text { Делегирование решений } \\
\text { - Сокращение иерархических } \\
\text { - } \text { Сровней } \\
\text { Структуры с ориентацией на } \\
\text { клиента } \\
\text { Структурные интеграцион- } \\
\text { ные инструменты } \\
\text { - Информационная технология } \\
\text { Системы стимулирования } \\
\text { труда и служебного продви- } \\
\text { жения }\end{array}$ & 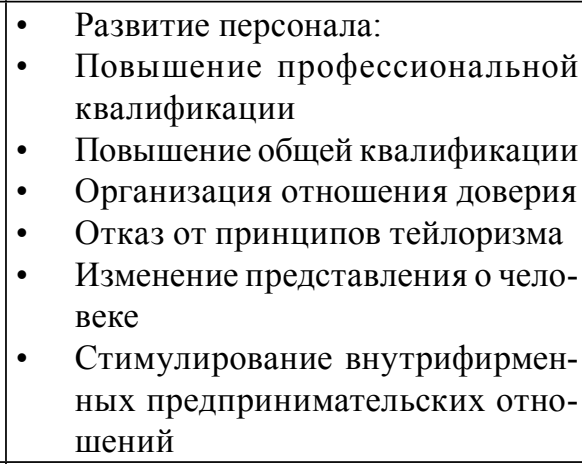 & 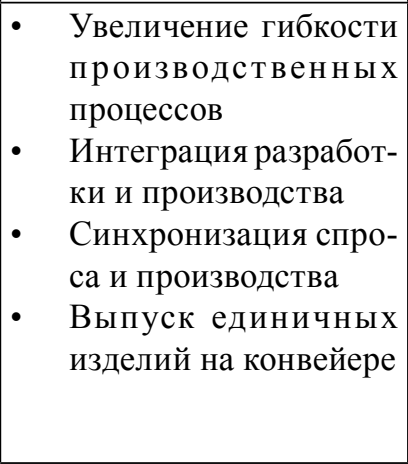 \\
\hline $\begin{array}{l}\text { Интег- } \\
\text { ральные } \\
\text { органи- } \\
\text { зационные } \\
\text { концепции }\end{array}$ & $\begin{array}{ll}\text { • } & \text { Сегментирование хозяйствен- } \\
\text { - } & \text { Кой деятельности } \\
& \text { Концепция центров, прибыли, } \\
\text { - } & \text { Уатрат и др. } \\
\text { - } & \text { Оптавление координацией } \\
\text { Опация процессов }\end{array}$ & - Развитие фирменной культуры & \\
\hline
\end{tabular}

Таблииа 2.

Структура компании ПНГДК

\begin{tabular}{|c|c|c|}
\hline Предприятие & Основные функции предприятия & Численность* \\
\hline ПНГДК & Управление, консолидация, отчетность & 178 шт. ед. \\
\hline Бурение 1 & Бурение скважин на суше, ремонт & 856 шт. ед. \\
\hline Бурение 2 & Бурение скважин в море, ремонт & 959 шт. ед. \\
\hline Разведка & Разведочное бурение, ремонт & 782 шт. ед. \\
\hline Логистика & Перевозка материалов и рабочих & 626 шт. ед. \\
\hline Хранение & Прием, хранение и выдача материалов & 101 шт. ед. \\
\hline Обслуживание & Монтаж буровых установок, ремонт & 278 шт. ед. \\
\hline Цементирование & Цементирование и подготовка скважин & 268 шт. ед. \\
\hline & Итого & 4,048 шт. ед. \\
\hline
\end{tabular}

* Численность предприятий указана на 1 сентября 2012 года. Источник - штатные расписания предприятий.

прием, хранение и выдачу материалов, выполняемые предприятием Хранение, перевозку материалов и рабочих, выполняемую предприятием Логистика, монтаж буровых установок, выполняемое предприятием Обслуживание, разведочное бурение скважин, выполняемое предприятием Разведка, бурение скважин, выполняемое предприятиями Бурение 1 или Бурение 2 в зависимости от работы на суше или на море и финальное цементирование скважин, выполняемое предприятием Цементирование.

Тем не менее, все предприятия имеют схожую линейно-функциональную организационную струк- туру, которая включает ряд аналогичных отделов (см. Таблицу 3).

Из предоставленных данных можно сделать вывод о возможной централизации ряда отделов, которые на данный момент выведены отдельно в каждом предприятии. Наиболее ярким примером такого отдела является отдел бухгалтерского учета и отчетности. Тем более что возможная централизация ряда отделов подкреплена непропорциональным соотношением между сотрудниками отделов и начальниками/заместителями, так как на текущий момент на 1 начальника/заместителя в среднем по отделам, 
DOI: $10.7256 / 2073-8560.2014 .3 .11919$

При цитировании этой статьи сноска на доі обязательна

\section{Национальная безопасность - № 3(32) • 2014}

Таблища 3.

Общая численность аналогичных отделов управления предприятий“

\begin{tabular}{|c|c|c|c|}
\hline Название отделов & $\begin{array}{c}\text { Сотрудники, } \\
\text { шт. ед. }\end{array}$ & $\begin{array}{c}\text { Начальники } \\
\text { и заместители, } \\
\text { шт. ед. } \\
\end{array}$ & $\begin{array}{c}\text { Сотрудников } \\
\text { на } 1 \text { начальника/ } \\
\text { заместителя, шт. ед. }\end{array}$ \\
\hline Отделы кадров и социальной защиты & 29 & 17 & 1.7 \\
\hline Отделы труда и заработной платы & 20 & 9 & 2.2 \\
\hline Геологические службы & 19 & 9 & 2.1 \\
\hline Операционные отделы & 15 & 9 & 1.7 \\
\hline Отделы экологии & 9 & 5 & 1.8 \\
\hline Отделы охраны труда и безопасности & 16 & 9 & 1.8 \\
\hline Отделы материально-технического снабжения & 31 & 13 & 2.4 \\
\hline Канцелярии и административные отделы & 33 & 7 & 4.7 \\
\hline Отделы бухгалтерского учета и отчетности & 52 & 19 & 2.7 \\
\hline Отделы механиков & 20 & 8 & 2.5 \\
\hline Отделы энергетиков & 18 & 5 & 3.6 \\
\hline Технико-технологические службы & 33 & 13 & 2.5 \\
\hline Отделы транспорта & 11 & 5 & 2.2 \\
\hline Руководство и управление аппаратом & 0 & 82 & 0.0 \\
\hline Итого & 306 & 210 & 1.5 \\
\hline
\end{tabular}

* В таблице приведена общая численность аналогичных отделов по всем дочерним предприятиям, включая ПНГДК

представленным в Таблице 3, приходится до 2,5 сотрудника, не учитывая руководство и управлением аппаратом. Хотя по норме управляемости в среднем на 1 начальника/заместителя должно приходиться до 9 сотрудников ${ }^{5}$.

Однако, в отличие от начальников и заместителей для анализа численности сотрудников отделов необходимы данные об основных трудозатратах, которые состоят из ежедневно выполняемых операций. При расчете ежедневно выполняемых операций необходимо учитывать следующие факторы: время на проведение одной операции, время на подготовку к операции, время на подготовку отчетности о выполненной работе, если таковая имеется, а также резерв на непредвиденные обстоятельства. Кроме этого необходимо учесть коэффициент на отпуска и болезни, значение которого зависит от многих факторов, таких как условия работы, сезонность отпусков, здоровья и семейного положения сотрудников, а также специфические коэффициенты, если таковые имеются. Пример специфического коэффициента является коэффициент, учитывающий удельный вес работ по бухгалтерскому учету и отчетности,

5 Быкова А. Организационные структуры управления // Успешный бизнес. Мастер класс / М.: Олма-пресс Инвест: Институт экономических стратегий, 2003, стр. 118 которая выполняется при помощи программного обеспечения ${ }^{6}$.

Ниже автор приводит таблицу с расчетом необходимой численности централизованного отдела бухгалтерского учета и отчетности (см. Таблицу 4).

Исходя из данных по основным трудозатратам, можно сделать заключение, что на выполнение ежемесячного объема работы требуется 113,668 минут в месяц с учетом резерва, составляющего $15 \%$ от рабочего времени.

Месячный фонд рабочего времени, не учитывающий ежегодный отпуск, определяется по следующей формуле:

$$
\mathrm{X}=((\mathrm{Y}-365) * \mathrm{~N} * 60) / 12
$$

Где: $\mathrm{X}$ - месячный фонд рабочего времени (минут), Y — количество выходных и праздничных дней, $\mathrm{N}$ - количество часов в рабочем дне

Используя фактические данные, производим расчет:

$$
((124-365) * 8 * 60) / 12=9,640 \text { минут }
$$

Необходимый штат сотрудников, учитывающий начальников и заместителей, находится по следующей формуле:

$$
\mathrm{M}=(\mathrm{Z} / \mathrm{X}) * \mathrm{Q} * \mathrm{~L} * \mathrm{C}
$$

\footnotetext{
6 Синеок О. Как рассчитать оптимальный бухгалтерский штат // Финансовый практикум 2010. №31 / К.: ИКК «Баланс-Клуб», 2010, стр. 22-24.
} 
Таблица 4.

Расчет месячного объема работы отделов бухгалтерского учета и отчетности

\begin{tabular}{|c|c|c|c|}
\hline Основные трудозатраты & $\begin{array}{l}\text { В месяц. } \\
\text { Единиц }\end{array}$ & $\begin{array}{l}\text { Обработка одной } \\
\text { позиции, минут* }\end{array}$ & $\begin{array}{l}\text { Итого, } \\
\text { Минут }\end{array}$ \\
\hline Накладные на приход материалов & 694 & 15 & 10,410 \\
\hline Накладные на внутренние перемещения материалов & 3,028 & 15 & 45,420 \\
\hline Накладные на выпуск материала со склада & 345 & 15 & 5,175 \\
\hline Доверенности (колпит) & 428 & 5 & 2,140 \\
\hline Внутренние доверенности & 100 & 20 & 2,000 \\
\hline Акты & 200 & 5 & 1,000 \\
\hline Приказы по основным средствам & 25 & 5 & 125 \\
\hline Письма (исходящие) & 20 & 10 & 200 \\
\hline Ремонтные сметы & 6 & 20 & 119 \\
\hline Счета/фактуры & 50 & 15 & 750 \\
\hline Инвойсы & 100 & 10 & 1,000 \\
\hline Контракты & 50 & 20 & 1,000 \\
\hline Путевые листы & 2,350 & 5 & 11,749 \\
\hline Табеля учета рабочего времени & 561 & 30 & 16,830 \\
\hline Приказы на отпуск, больничные & 50 & 15 & 750 \\
\hline Остальное (резерв) & 1,000 & 15 & 15,000 \\
\hline \multicolumn{3}{|r|}{ Итого } & 113,668 \\
\hline
\end{tabular}

* Данные по продолжительности обработки одной позиции получены через хронометраж рабочего времени

Где: Z - месячный объем работы (минут) ,X месячный фонд рабочего времени (минут), Q- коэффициент подмены, L — коэффициент, учитывающий удельный вес работ по бухгалтерскому учету и отчетности, С - коэффициент, учитывающий подготовку отчетности и дополнительной работы

Используя полученные данные, производим расчет:

$$
(113,668 / 9,640) * 1.3 * 1.2 * 1.3=24 \text { шт. ед. }
$$

Итого, на текущий момент работа, которая по приведенному выше расчету должна выполняться 24 сотрудниками, выполняется 71 сотрудником по всем предприятиям ПНГДК как показано в Таблице 3. Централизация отделов бухгалтерского учета и отчетности с последующей оптимизацией 47 штатных единиц, основываясь на данных приведенных в расчете, позволит ежегодно экономить в пересчете на российский рубль до 30 млн. рублей с учетом социальных отчислений, составляющих суммарно $22 \%$ в Республике Азербайджан.

Данный подход можно применить для большинства отделов указанных в Таблице 2 , что и было сделано в ходе проведения проекта (см. Таблицу 5).

Централизация аналогичных отделов управления предприятий позволила оптимизировать 264 штатных единиц, что обеспечило ежегодную экономию в пересчете на российский рубль в размере до 156 млн. рублей с учетом социальных отчислений.

По мнению автора на сегодняшний день существует множество технических решений, начиная с простейшего перехода с бумажной отчетности на электронную, внедрения систем позиционирования, спутниковой связи и заканчивая комплексными решениями, как например SAP и Oracle. Данные технологические решения позволяют минимизировать необходимость физического присутствия полного управленческого состава на дочерних предприятиях.

Опыт предприятия ПНГДК в части централизации и минимизации дублирования управленческих функций, а также сокращения трудозатрат на консолидацию данных, обрабатываемых в аналогичных отделах других дочерних предприятий, актуален не только для предприятий нефтегазодобывающей отрасли, но и для других отраслей, так как показывает, что нормативы, которые были разработаны в СССР, в наше время, учитывая наличие технических решений, потеряли свою актуальность и не годятся для объективной оценки загрузки персонала.

В данной статье автором был рассмотрен метод объективной оценки загрузки персонала на 
DOI: $10.7256 / 2073-8560.2014 .3 .11919$

При цитировании этой статьи сноска на доі обязательна

\section{Национальная безопасность - № 3(32) • 2014}

Таблища 5.

Численность централизованных отделов управления предприятий

\begin{tabular}{|c|c|c|c|}
\hline Название отделов & $\begin{array}{c}\text { Сотрудники, } \\
\text { шт. ед. }\end{array}$ & $\begin{array}{c}\text { Начальники } \\
\text { и заместители, } \\
\text { шт. ед. } \\
\end{array}$ & $\begin{array}{c}\text { Сотрудников } \\
\text { на } 1 \text { начальника/ } \\
\text { заместителя, шт. ед. }\end{array}$ \\
\hline Отделы кадров и социальной защиты & 19 & 3 & 6.3 \\
\hline Отделы труда и заработной платы & 16 & 2 & 8.0 \\
\hline Геологические службы & 19 & 2 & 9.5 \\
\hline Операционные отделы & 12 & 6 & 2.0 \\
\hline Отделы экологии & 7 & 2 & 3.5 \\
\hline Отделы охраны труда и безопасности & 16 & 2 & 8.0 \\
\hline Отделы материально-технического снабжения & 20 & 3 & 6.7 \\
\hline Канцелярии и административные отделы & 14 & 0 & $\mathrm{n} / \mathrm{a}$ \\
\hline Отделы бухгалтерского учета и отчетности & 21 & 3 & 7.0 \\
\hline Отделы механиков & 15 & 3 & 5.0 \\
\hline Отделы энергетиков & 15 & 3 & 5.0 \\
\hline Технико-технологические службы & 18 & 3 & 6.0 \\
\hline Отделы транспорта & 10 & 2 & 5.0 \\
\hline Руководство и управление аппаратом & 0 & 16 & 0.0 \\
\hline Итого & 202 & 50 & 4.0 \\
\hline
\end{tabular}

примере отдела бухгалтерского учета и отчетности, а также всего предприятия ПНГДК в целом. Данный метод универсален и позволяет учесть все факторы, оказывающие влияние на повседневную работу персонала. Но для использования данного метода необходимо проведение комплекса экспериментов и показательных работ по оценке трудозатрат и времени выполнения текущих операций. Кроме того, большая доля успеха зависит от эффективного сотрудничества с персоналом предприятия.

В итоге, на основании данного исследования автор формулирует ряд выводов:

1. Сегодня на предприятиях нефтегазовой отрасли, работающих на постсоветском пространстве и созданных путем объединения производственных мощностей, не всегда уделяется должное внимание эффективности и экономичности системы управления по ряду причин, в том числе и из-за высокой рентабельности отрасли, государственной поддержки и устойчивого положения предприятий.
2. С учетом долгосрочных перспектив развития нефтегазовой отрасли отсутствие экономичных и эффективных структур управления уменьшает привлекательность для инвестирования, увеличивает издержки предприятий, усложняет процесс модернизации производства, уменьшает гибкость системы предприятий, что делает данные предприятия более уязвимыми перед зарубежными предприятиями-аналогами.

3. Предлагается метод объективной оценки загрузки персонала, который является универсальным и позволяет учесть все факторы, оказывающие влияние на повседневную работу персонала. Эффективность данного метода доказана на конкретном примере, рассматриваемом в этой статье.

4. Даются рекомендации относительно основных направлений централизации функций управления предприятием: сокращение уровней управления, минимизация дублирования управленческих функций, оптимизация текущей организационной структуры и повышения загрузки управленческого персонала предприятия.

\section{Библиография:}

1. Миронов Л.А. Состояние и развитие нефтегазового комплекса стран СНГ // НГСПинформ 2011, №11 / М.: Издательско-производственный комплекс «МИнИн Центр», 2011, стр. 1-5.

2. Мазур И.И., Шапиро В.Д. Реструктуризация предприятий и компаний // Справочное пособие // М.: Высшая школа, 2000, стр. 24-25. 
3. Bowman C., Asch D. Strategic management. L., 1987. P. 514.

4. Быкова А. Организационные структуры управления // Успешный бизнес. Мастер класс / М.: Олма-пресс Инвест: Институт экономических стратегий, 2003, стр. 118.

5. Синеок О. Как рассчитать оптимальный бухгалтерский штат // Финансовый практикум 2010. №31 / К.: ИКК «Баланс-Клуб», 2010, стр. 22-24.

\section{References:}

1. Mironov L.A. Sostoyanie i razvitie neftegazovogo kompleksa stran SNG // NGSPinform 2011, №11 / M.: Izdatel'skoproizvodstvennyi kompleks «MInIn Tsentr», 2011, str. 1-5.

2. Mazur I.I., Shapiro V.D. Restrukturizatsiya predpriyatii i kompanii // Spravochnoe posobie // M.: Vysshaya shkola, 2000, str. 24-25.

3. Bowman S., Asch D. Strategic management. L., 1987. P. 514.

4. Bykova A. Organizatsionnye struktury upravleniya // Uspeshnyi biznes. Master klass / M.: Olma-press Invest: Institut ekonomicheskikh strategii, 2003, str. 118.

5. Sineok O. Kak rasschitat' optimal'nyi bukhgalterskii shtat // Finansovyi praktikum 2010. №31 / K.: IKK «BalansKlub», 2010, str. 22-24. 